\title{
Environmental Ethics and Pollution by Tobacco
}

\author{
Jyotsna Lal Ph.D *, Niranjan Swaroop, \\ Associate Professor, Department of Chemistry, Christ Church P.G College. Kanpur. U.P. \\ Assistant Professor, Department of Mathematics, Christ Church P.G College . Kanpur. U.P.
}

\begin{abstract}
Burning tobacco is the main source of indoor pollution in the developed world. Tobacco smoke contains about 4,000 chemicals including carcinogens, irritants and toxic gases. Nicotine, benzene and benzo(a)pyrene. The gas phase includes carbon monoxide, ammonia, dimethylnitrosamine, formaldehyde, hydrogen cyanide and acrolein. Methyl bromide, an ozone-depleting chemical commonly used to fumigate the soil prior planting tobacco seedlings. Tobacco growers are susceptible to an occupational illness known as green tobacco sickness. This is caused by the absorption of nicotine through the skin from contact with wet tobacco leaves. Nicotine is a risk factor for oral cancer, adult periodontal diseases and congenital defects such as cleft lip and palate in children. Nicotine causes heart arteries to harden, tend to shrink, thickening of blood increases cholesterol deposition leading to heart attack. Smoking causes lung cancer. Breathing other people's smoke is called passive, involuntary or secondhand smoking. The non-smoker breathes "side stream" smoke from the burning tip of the cigarette and "mainstream" smoke that has been inhaled and then exhaled by the smoker. Second hand smoke (SHS) is a major source of indoor air pollution.
\end{abstract}

\section{Introduction}

Environmental ethics is a branch of applied philosophy that studies the conceptual foundations of environmental values as well as more concrete issues surrounding societal attitudes, actions, and policies to protect and sustain biodiversity and ecological systems, considers extending the traditional boundaries of ethics from solely including humans to including the non-human world. It exerts influence on a large range of disciplines including environmental law, environmental sociology, eco theology, ecological economics, ecology and environmental geography.

Environmental ethics builds on scientific understanding by bringing human values, moral principles, and improved decision making into conversation with science. It was Earth Day in 1970 that helped to develop environmental ethics in the US, and soon thereafter the same ethics were developed in other countries including Canada and North America. This is important because the ethics of the environment are of major concern these days. The acts of humans lead to environmental pollution. The stronger demand for resources is also a factor that contributes to the problem as we all need food and shelter. When these things are so desired and need the natural balance of the environment is disturbed. Engineering developments are resulting in resource depletion and environmental destruction. There are several environmental issues that have created havoc on our environment and human life. If ignored today, these ill effects are sure to curb human existence in the near future. Human beings are considered to be the most intelligent species living on earth. This could be why it is the only species on earth which has civilized itself over the decades to a large extent. Today, human beings boast as being superior to all other animals but what is the use of such great intelligence when environment ethics are not followed? Environmental ethics are a key feature of environmental studies that establishes relationship between humans and the earth. With environmental ethics, you can ensure that you are doing your part to keep the environment safe and protected. Environmental ethics believe that humans are a part of society as well as other living creatures, which includes plants and animals. These items are a very important part of the world and are considered to be a functional part of human life. Thus, it is essential that every human being respect and honor this and use morals and ethics when dealing with these creatures. It is the responsibility of all to ensure that environmental ethics are being met. It is somewhat difficult to make adjustments that are necessary to ensure that you are following all environmental ethics. Ethics plays an important role in our society today, and environmental ethics and business ethics must be considered. This has become more prevalent in today's society; environmental ethics studies the relation of human beings and the environment and how ethics play a role in this. Environment ethics has produced around environmental philosophy. Many scientists have taken up the belief of philosophical aspect of environmental hazards thus giving rise to environment ethics. Currently environment ethics has become the major concern for the mankind. The major environmental issues include Overpopulation, Industrial and Household Waste, Acid Rain, Climate change, Ozone Layer Depletion, Urban Sprawl, Genetic Engineering, Deforestation and Global Warming. These environmental issues have taken toll on our environment and we've already started seeing some disastrous effects in the form of effect of health on humans, rise in sea level, depletion of non-renewable resources, melting of glaciers, extinction of species, polluted landfills, toxic dust, decreasing soil fertility, rise in Pollution specially air, soil and water pollution . 


\section{Pollution By Tobacco}

Burning tobacco is the main source of indoor pollution in the developed world. Tobacco smoke contains about 4,000 chemicals including carcinogens, irritants and toxic gases. Nicotine, benzene and benzo(a) pyrene. The gas phase includes carbon monoxide, ammonia, dimethylnitrosamine, formaldehyde, hydrogen cyanide and acrolein. About $95 \%$ of the smoke is made up of gases, chiefly nitrogen, oxygen, and carbon dioxide. In experiments, these vapor-phase components are separated from the particulate phase by a glass-fiber filter. The particulate phase contains at least 3500 com-pounds and most of the carcinogens. There are 55 carcinogens (Table 1, A) in cigarette smoke that have been evaluated by the International Agency for Research on Cancer (IARC) and for which there is "sufficient evidence for carcinogenicity" in either laboratory animals or humans Other carcinogens not evaluated by the IARC may also be present. For example, among the PAHs, multiple alkylated and high-molecular-weight compounds have been detected but are incompletely characterized with respect to their carcinogenicity. Individual pulmonary carcinogens in cigarette smoke, selected from the classes of carcinogens in Table 1, A, are listed in Table 1, B. The 20 compounds included in this list have been found convincingly to induce lung tumors in at least one animal species and have been positively identified in cigarette smoke the pesticides commonly used are aldicarb and chlorpyrifos, both highly toxic substances. Methyl bromide, an ozone-depleting chemical, is also commonly used to fumigate the soil prior to planting tobacco seedlings. In 1997, over 5.5 million pounds of methyl bromide were applied to tobacco fields worldwide. The effects of these chemicals are not monitored generally but it is known that they leach into the soil and find their way into streams, rivers, and food chains. These substances may indirectly cause the genetic selection of pesticide-resistant mosquitoes or flies, making the control of diseases such as malaria much more difficult.

Tobacco growers are susceptible to an occupational illness known as green tobacco sickness. This is caused by the absorption of nicotine through the skin from contact with wet tobacco leaves. Symptoms of GTS include nausea, weakness, dizziness and abdominal cramps, and fluctuations in blood pressure and heart rates It is not known exactly how many tobacco workers are affected by green tobacco sickness but one study of migrant workers in North Carolina USA suggests that $41 \%$ of the workers get the illness at least once during harvest season.

Dr Judith MacKay, Director of the Asian Consultancy on Tobacco Control in Hong Kong, claims that tobacco's "minor" use of land denies 10 to 20 million people of food. "Where food has to be imported because rich farmland is being diverted to tobacco production, the government will have to bear the cost of food imports," she points out.

\section{Effect of Chewing Tobacco on the Human Body}

Nicotine is a risk factor for oral cancer, adult periodontal diseases and congenital defects such as cleft lip and palate in children. Nicotine causes heart arteries to harden, tend to shrink, thickening of blood, increases cholesterol deposition Leading to heart attack. Smoking causes lung cancer Breathing other people's smoke is called passive, involuntary or secondhand smoking. The non-smoker breathes "side stream" smoke from the burning tip of the cigarette and "mainstream" smoke that has been inhaled and then exhaled by the smoker. Secondhand smoke (SHS) is a major source of indoor air pollution. Among the multiple components of tobacco smoke, 20 carcinogens convincingly cause lung tumors in laboratory animals or humans and are, therefore, likely to be involved in lung cancer induction. Of these, polycyclic aromatic hydrocarbons and the tobacco-specific nitrosamine 4-(methylni-trosamino)-1-(3-pyridyl)-1-butanone are likely to play major roles Molecular epidemiologic studies have demonstrated an association between environmental pollutants and in utero developmental damage. Among the environmental pollutants to which developing fetuses are reported to be vulnerable is environmental tobacco smoke (ETS). ETS is a complex mixture of volatiles and particulate matter comprising numerous compounds, including polycyclic aromatic hydrocarbons (PAHs), which cause oxidative damage. Maternal ETS exposure has been found to be an important risk factor for reduced birth weight, small for gestational age, and premature delivery.

Apart from being a health hazard the economic costs of tobacco use are equally devastating. In addition to the high public health costs of treating tobacco-caused diseases, tobacco kills people at the height of their productivity, depriving families of breadwinners and nations of a healthy workforce. Tobacco users are also less productive while they are alive due to increased sickness.

\section{Effect of Passive Smoking on the Human Body}

Some of the immediate effects of passive smoking include eye irritation, headache, cough, sore throat, dizziness and nausea. Adults with asthma can experience a significant decline in lung function when exposed, while new cases of asthma may be induced in children whose parents smoke. Short term exposure to tobacco smoke also has a measurable effect on the heart in non-smokers. Just 30 minutes exposure is enough to reduce coronary blood flow. In the longer term, passive smokers suffer an increased risk of a range of smoking-related 
diseases. Non-smokers, who are exposed to passive smoking in the home, have a 25 per cent increased risk of heart disease and lung cancer.] A major review by the Government-appointed Scientific Committee on Tobacco and Health (SCOTH) concluded that passive smoking is a cause of lung cancer and ischemic heart disease in adult non-smokers, and a cause of respiratory disease, cot death, middle ear disease and asthmatic attacks in children. A more recent review of the health impacts of passive smoking by the International Agency for Research on Cancer (IARC) noted that "the evidence is sufficient to conclude that involuntary smoking is a cause of lung cancer in never smokers". UNCTAD 2004 [4]

Whilst the relative health risks from passive smoking are small in comparison with those from active smoking, because the diseases are common, the overall health impact is large. The British Medical Association has conservatively estimated that secondhand smoke causes at least 1,000 deaths a year in the UK. However, the true figure is likely to be much higher. Professor Konrad Jamrozik of Imperial College London estimated that domestic exposure to secondhand smoke causes at least 3,600 deaths annually from lung cancer, heart disease and stroke combined, while exposure at work leads to approximately 700 deaths from these causes. Jamrozik also estimates 49 deaths - or about 1 a week - from exposure at work in the hospitality trades. In the population aged 65 or older, passive smoking is estimated to account for 16,900 deaths annually. 9,700 are due to stroke, where current evidence of health effects is weakest.[6-30]

\section{Tobacco Use}

According to the most recent Government of India's National Sample Survey data, there are 184 million tobacco consumers in India. About $40 \%$ of them use smokeless tobacco, 20\% consume cigarettes, and another $40 \%$ smoke beedis. Smokeless tobacco use includes pan masala and chewing of tobacco in different forms. Tobacco is also smoked using indigenous devices like hooka, chhutta or dhumti in different parts of the country. Thus, in contrast to the other parts of the world, tobacco is used in a variety of ways in India, which include smoking and smokeless tobacco use. [Gupta.Agarwal2001]

Tobacco use is the most preventable cause of premature death in the US $[17,18]$ and is responsible for about $30 \%$ of all cancer deaths. Cigarette smoking is associated with lung cancer as well as with cancers of the lip and oral cavity, larynx, esophagus, stomach, colon, rectum, pancreas, cervix, bladder, and kidney. Both incidence and death rates from lung cancer are higher among African American men than among white men, even though African Americans begin smoking at an older age and smoke fewer cigarettes per day. Susceptibility to developing lung cancer from smoking may be affected by the type of cigarettes smoked. More African Americans smoke mentholated cigarettes, 24 which have been shown to have higher carbon monoxide concentrations than regular cigarettes and may be associated with a greater absorption of nicotine.

An estimated 3,000 young persons begin smoking each day.[Cancer Facts \& Figures] For over a decade, African American youth have had the lowest prevalence of cigarette smoking compared with other racial and ethnic groups. According to the Youth Risk Behavior Surveillance Survey (YRBSS) [National Research Council Committee 1986]

Tobacco use is the most preventable cause of premature death in the US Study of youth smoking patterns reflect different aspects of initiation, beginning with experimentation with the tobacco product experimentation and progressing to regular smoking and nicotine dependence. According to Youth Risk Behavior surveillance survey [YRBSS] 40\% of High school student currently use tobacco products [cigarettes, chewing tobacco, snuff] And 24.9\% had smoked a whole cigarette before age 13 in, more than $34.8 \%$ High School smoke cigarettes currently. Worldwide $17.9 \%$ male and 15.6 female High school students smoked cigarette frequently [Cancer Facts \&Figures2003-04]

In India the study populations included English medium school, Municipal schools and college students, medical students and street children. The prevalence of smoking has been found to vary from 6.9 to $22.5 \%$ among the male school and college students. In the observation tables $5 \& 6$. Among the girls, the prevalence is considerably low varying from $0-2.3 \%$. In fact, tobacco use, especially smoking, is a relatively new habit among the Indian female students, noticed only during the last 10-15 years [Chadda RK, Sengupta $\mathrm{SN}]$

Regardless of race and ethnicity, male students were more likely to use smokeless tobacco than female students, other products smoked by youth include bidis, these are small filter less, flavored cigarettes exported from India bidi smokers inhale more often and deeply due to lower combustibility of the leaf wrapper and breathe in greater quantity of tar and toxins than cigarette smokers. Like all tobacco products bidis cause cancer. [Rohit Sharma2010]

These studies suggest that bezine like peptides and their receptors play a role in the promotion of lung carcinogenesis. Important differences in susceptibility to lung cancer exist between men and women. The risk for all major lung cancer types is consistently higher in women than in men at every level of exposure to cigarette smoke; odds ratios for an association of lung cancer with smoking are 1.2-fold to 1.7-fold higher for women than for men, depending on the histologic type of lung cancer. Factors such as differences in baseline 
ex-posure, smoking history, or body size do not account for the increased risk, which is likely due to a higher susceptibility to the effects of tobacco carcinogens in women. The airways of females also exhibit a higher degree of bronchial responsiveness to cigarette smoke compared with those of males of all age groups, and airways of females appear more susceptible to adverse effects of cigarette smoke than those of males [Jindal SK, Jha LK.1996] Adolescents and children are the prime targets of the tobacco industry when recruiting new smokers. About 20 million children of ages 10-14 are estimated to be tobacco addicted according to a survey done by the National Sample Survey Organization of the Indian Government. A number of factors influence the use of tobacco by children and teenagers. Some of these are the family history of tobacco use by elders, peer influence, experimentation, easy access to such products, personality factors, underlying emotional and psychological problems, accompanied risk-taking behaviors, and most importantly, the aggressive marketing strategies of the tobacco industry. Adolescents typically become addicted to nicotine while still being teenagers. Usual interval between the first cigarette consumption and daily smoking is 1-2 year(s).Table 3 .

\section{Socioeconomic Status}

Cancer affects all segments of the population. Lower survival rates and higher mortality; however, often disproportionately affect those of lower socioeconomic status for many reasons, including limited access to health care. more likely to be diagnosed with a later stage of cancer, limited education may be associated with later detection, since the less educated are less likely to know the importance of symptoms that could lead to an early diagnosis. Late detection, in turn, may result in a lower cure rate and shorter survival. Tobacco is the second major cause of death in the world. It is currently responsible for the death of one in ten adults' worldwide (about 5 million deaths each year). If current smoking patterns continue, it will cause some 10 million deaths each year by 2025 . Half the person that smoke today that is about 650 million people will eventually be killed by tobacco. Tobacco is the fourth most common risk factor for disease worldwide. [Table3] The economic costs of tobacco use are equally devastating. In addition to the high public health costs of treating tobacco-caused diseases, tobacco kills people at the height of their productivity, depriving families of breadwinners and nations of a healthy workforce. Tobacco users are also less productive while they are alive due to increased sickness. A 1994 report estimated that the use of tobacco resulted in an annual global net loss of US\$ 200 thousand million, a third of this loss being in developing countries. Tobacco and poverty are inextricably linked. [UNCTAD's] Many studies have shown that in the poorest households in some low-income countries as much as $10 \%$ of total household expenditure is on tobacco. This means that these families have less money to spend on basic items such as food, education and health care. In addition to its direct health effects, tobacco leads to malnutrition, increased health care costs and premature death. It also contributes to a higher illiteracy rate, since money that could have been used for education is spent on tobacco instead. Tobacco's role in exacerbating poverty has been largely ignored by researchers in both fields.

\section{Conclusion}

Tobacco is the second major cause of death in the world. It is currently responsible for the death of one in ten adults worldwide (about 5 million deaths each year). If current smoking patterns continue, it will cause some 10 million deaths each year by 2025 . Half the person that smoke today that is about 650 million peoplewill eventually be killed by tobacco. Tobacco is the fourth most common risk factor for disease worldwide. The economic costs of tobacco use are equally devastating. In addition to the high public health costs of treating tobacco-caused diseases, tobacco kills people at the height of their productivity, depriving families of breadwinners and nations of a healthy workforce. Tobacco users are also less productive while they are alive due to increased sickness. A 1994 report estimated that the use of tobacco resulted in an annual global net loss of US\$ 200 thousand million, a third of this loss being in developing countries. Tobacco and poverty are inextricably linked. Many studies have shown that in the poorest households in some low-income countries as much as $10 \%$ of total household expenditure is on tobacco. This means that these families have less money to spend on basic items such as food, education and health care. In addition to its direct health effects, tobacco leads to malnutrition, increased health care costs and premature death. It also contributes to a higher illiteracy rate, since money that could have been used for education is spent on tobacco instead. Tobacco's role in exacerbating poverty has been largely ignored by researchers in both fields. The WHO Oral Health Programme aims to control tobacco-related oral diseases and adverse conditions through several strategies. Within WHO, the Programme forms part of the WHO tobacco-free initiatives, with fully integrated oral health-related programmes. Externally, the Programme encourages the adoption and use of WHO tobacco-cessation and control policies by international and national oral health organizations. Primary partners are WHO Collaborating Centers in Oral Health and NGOs who are in official relations with WHO, i.e. the International Association for Dental Research (IADR) and the FDI World Dental Federation. There are several ethical, moral, and practical reasons why oral health professionals should strengthen their contributions to tobacco-cessation programmes The most cost-effective strategies are population-wide public policies, like bans on direct and indirect tobacco 
advertising, tobacco tax and price increases, smoke-free environments in all public and workplaces, and large clear graphic health messages on tobacco packaging Lee Jong-wook, WHO 2004 [1]

\section{Acknowledgements}

Jyotsna Lal is thankful to Dr Israel Principal,United College of Ascession. Selly Oaks University of Birmingham, Birmingham U.K for permission to use the library to research this Article

\section{References}

[1]. Lee Jong-wook, WHO Director-General's message Tobacco and poverty: a vicious circle @ Copyright 2004 World Health Organization

[2]. Handbook of Environmental Data on Organic Clinical Data Vol 2

[3]. Encyclopedia of Clinical Toxicology pp744-45

[4]. UNCTAD's eleventh quadrennial conference held in Sao Paulo, Brazil on 13-18 June 2004. @ Copyright 2004 World Health Organization

[5]. World Health Organization 2004 World No Tobacco Day 2004 - 31 May Globalization of the Tobacco Epidemic | Tobacco Control and Development 17 June 2004, 10h00 - 13h00, Room A @ C Copyright 2004 World Health Organization

[6]. Respiratory health effects of passive smoking. EPA/600/6-90/006F United States Environmental Protection Agency, 1992

[7]. Fielding, JE and Phenow, KJ. New England J. of Medicine 1988; 319: 1452-60.

[8]. Otsuka, R. Acute effects of passive smoking on the coronary circulation in healthy young adults. JAMA 2001; 286: 436-441 ]

[9]. Law MR et al. Environmental tobacco smoke exposure and ischaemic heart disease: an evaluation of the evidence. BMJ 1997; 315: 973-80. [View abstract]

[10]. Hackshaw AK et al. The accumulated evidence on lung cancer and environmental tobacco smoke. BMJ 1997; 315: 980-88. [View abstract]

[11]. Report of the Scientific Committee on Tobacco and Health. Department of Health, 1998. [View document]

[12]. Tobacco smoke and involuntary smoking. IARC Monographs on the evaluation of carcinogenic risks to humans. Vol 83. Lyon, France, 2004. View summary

[13]. Whincup, $\mathrm{P}$ et al. Passive smoking and risk of coronary heart disease and stroke: prospective study with cotinine measurement. BMJ Online First June 2004 [View abstract]

[14]. Paper presented by Professor Konrad Jamrozik at RCP conference, 2004

[15]. General Household Survey 1998, Office for National Statistics, 1999

[16]. Strachan, DP and Cook, DG. Parental smoking and lower respiratory illness in infancy and early childhood. Thorax 1997; 52: 905-914.

[17]. Respiratory health effects of passive smoking. EPA/600/6-90/006F United States Environmental Protection Agency, 1992.

[18]. Health effects of exposure to environmental tobacco smoke. Report of the California EPA. NCI, 1999.]

[19]. International Consultation on ETS and Child Health. WHO/NCD/TFI/99.10, World Health Organization, 1999. ]

[20]. Smoking and the Young. Royal College of Physicians, 1992.

[21]. Nageris,B Effects of passive smoking on odour identification in children. J Otolaryngol. 2001; 30 (5): 263-5

[22]. Yolton, $\mathrm{K}$ et al. Exposure to environmental tobacco smoke and cognitive ability among US children. Abstracts Online. May 2002 View abstract

[23]. Health effects of exposure to environmental tobacco smoke. The report of the California Environmental Protection agency. Smoking and Tobacco Control Monograph 10, National Cancer Institute, 1999.

[24]. Gilliland FD et al. Thorax 2000; 55: 271-276 ]

[25]. Smoking Kills. A White Paper on Tobacco. The Stationery Office, 1998. ]

[26]. Lader, D and Meltzer, H. Smoking related behaviour and attitudes, 2002. Office for National Statistics, 2003

[27]. Workers still exposed to tobacco smoke at work. Press release, Smoke Free London, 2 December 2003.

[28]. Overwhelming backing for workplace smoking law. ASH press release 11 June 2004.

[29]. US Department of Health and Human Services, US Food and Drug Administration. Regulations restricting the sale and distribution of cigarettes and smokeless tobacco to protect children and adolescents. Federal Register 1996;61:44396-45318.

[30]. Bhacco, N.S et. al [1962-63] NMR Spectra Catalog

[31]. US Department of Health and Human Services. The health consequences of using smokeless tobacco: a report of the advisory committee to the Surgeon General. Bethesda, Maryland: US Department of Health and Human Services, Public Health Service, 1986.

[32]. CDC. Youth Risk Behavior Surveillance--United States, 1997. MMWR 1998;47(no. SS-3).

[33]. Maxwell JC Jr, Fenstermacher SD. The smokeless tobacco industry in 1997. The Maxwell Consumer Report. Richmond, Virginia: Davenport \& Company LLC, May 22, 1998.

[34]. Strachan DP, Cook DG. Health effects of passive smoking.6. Parental smoking and childhood asthma: longitudinal and case-control studies. Thorax 1998; 53: 204-12.[37] Lide DR, ed. CRC Handbook of chemistry and physics. 71st ed. Boca Raton, Florida: CRC Press, 1990.

[35]. Henningfield JE, Radzius A, Cone EJ. Estimation of available nicotine content of six smokeless tobacco products. Tob Control 1995;4: 57-61

[36]. Tomar SL, Henningfield JE. Review of the evidence that $\mathrm{pH}$ is a determinant of nicotine dosage from oral use of smokeless tobacco. Tob Control 1997;6: 219-25.

[37]. US House of Representatives. Smokeless tobacco ingredient list as of April 4, 1994. US House of Representatives, Report to Subcommittee on Health and the Environment, Committee on Energy and Commerce. Washington, DC: Patton, Boggs and Blow, May 3, 1994.

[38]. Djordjevic MV, Hoffmann D, Glynn T, Connolly GN. US commercial brands of moist snuff, 1994: I. Assessment of nicotine, moisture, and pH. Tob Control 1995;4:62-6.

[39]. Toxic effect of tobacco [nicotine] intake on the human body and identification of nicotine in tobacco by nmr spectroscopy Indian. J. Environmental Protection [2006]

[40]. European Respiratory Journal (DOI: 10.1183/09031936.06.00056305),

[41]. Molecular Psychiatry (DOI:10.1038/sj.mp.4001794) (Proceedings of the National Academy of Sciences, DOI: 10.1073/pnas.0509313103). 
[42]. Journal of Chemical Research in Toxicology (DOI: DOI: 10.1021/tx0340596) Pharmacogenetics (vol 10, p 483)

[43]. John R. Wagner Gas Chromatographic Determination of Nicotine Contained on Cambridge Filter Pads, ,Annual meeting of the Association of Official Analytical Chemists, October 1978

[44]. NIDA FACTS 2006 National Institute of drug abuse, National institute of health DHHS

[45]. US Department of Health and Human Services. Public Health Service Office on Smoking and Health. The health consequences of involuntray smoking. A Report of the Surgeon General, Washington, DC: US Government Printing Office, 1986.

[46]. US Environmental Protection Agency. Respiratory health effects of passive smoking: lung cancer and other disorders. Washington, DC: Office of Research and Development,1992,EPA/600/6-90/006F.

[47]. Jindal SK, Gupta D. The relationship between tobacco smoke and bronchial asthma. Indian J Med Res 2004; 120:443-53.

[48]. Gupta D, Aggarwal AN, Kumar R, Jindal SK. Prevalence of bronchial asthma and association with environmental tobacco smoke exposure in adolescent school children in Chandigarh, North India. J Asthma 2001; 38: 501-7.

[49]. Jindal SK, Gupta D, Singh AJ. Indices of morbidity and control of asthma in patients exposed to environmental tobacco smoke. Chest 1994; 106: 746-9.

[50]. Jindal SK, Gupta D, Chattopadhaya S, Kumar L. Environmental tobacco smoke exposure precipitates acute exacerbation in nonsmoker asthmatics. Lung India 1997; 15:168-72.

[51]. Jindal SK, Gupta D, D’ Souza GA, Kalra S. Bronchial responsiveness of non-smoking women exposed to environmental tobacco smoke or biomass fuel combustion. Indian J Med Res 1996; 104: 359-64.

[52]. Jindal SK, Jha LK. Gupta D. Bronchial hyper-responsiveness of women with asthma exposed to environmental tobacco smoke. Indian J Chest Dis Allied Sci 1999; 41: 75-82.

[53]. Aggarwal AN, Chaudhry K, Chhabra SK, D’Souza GA, Gupta D, Jindal SK, et al. Prevalence and risk factors for bronchial asthma in Indian adults: a multicentre study.Indian J Chest Dis Allied Sci 2006; 48: 13-22.

[54]. First MW. Costituents of side stream and main stream tobacco and markers to quantify exposure to them. In :Gammag RB, Kaye SV, editors. Indoor Air and Human Health. Chelsea MI: Lewis Publishers. 1985; 195-203.

[55]. Spengler JD, Dockery DW, Turner WA, Walfson JM, FerrisBG (Jr). Long term measurements of respirable sulfates and particles inside and outside homes. Atmos Environ 1981; 15:23-30.

[56]. National Research Council Committee on Passive Smoking. Environmental tobacco smoke: measuring exposures and assessing health effects. Washington, DC: National Academy Press. 1986.

[57]. California Environmental Protection Agency. Health effects of exposure to environmental tobacco smoke. Sacramento, CA: Office of Environmental Health Hazard Assessment; 1997.

[58]. Pirkle JL, Flegal KM, Bernert JT, Brody DJ, Etzel RA, Maurer KR. Exposure of the US population to environmental tobacco smoke: The Third National Health and Nutrition Examination Survey, 1988 to 1991. JAMA1996; 275: 1233-40.

[59]. US Census Bureau. Educational Attainment of the Population15 Years and Over by Age, Sex, Race, and Hispanic Origin: March 2000.536/tab01.pdf. Accessed January 15, 2003.

[60]. Lee Jong-wook, WHO Director-General's message Tobacco and poverty: a vicious circle @ C Copyright 2004 World Health Organization

[61]. Rohit Sharma , tobacco use by adolescents Ind J community medicine 35,2010

[62]. Cancer Facts \&Figures for African Americans is a publication of the American Cancer Society, Atlanta, Georgia. Cancer Facts \&Figures for African Americans is a publication of the American Cancer Society,Atlanta,Georgia.2003-2004

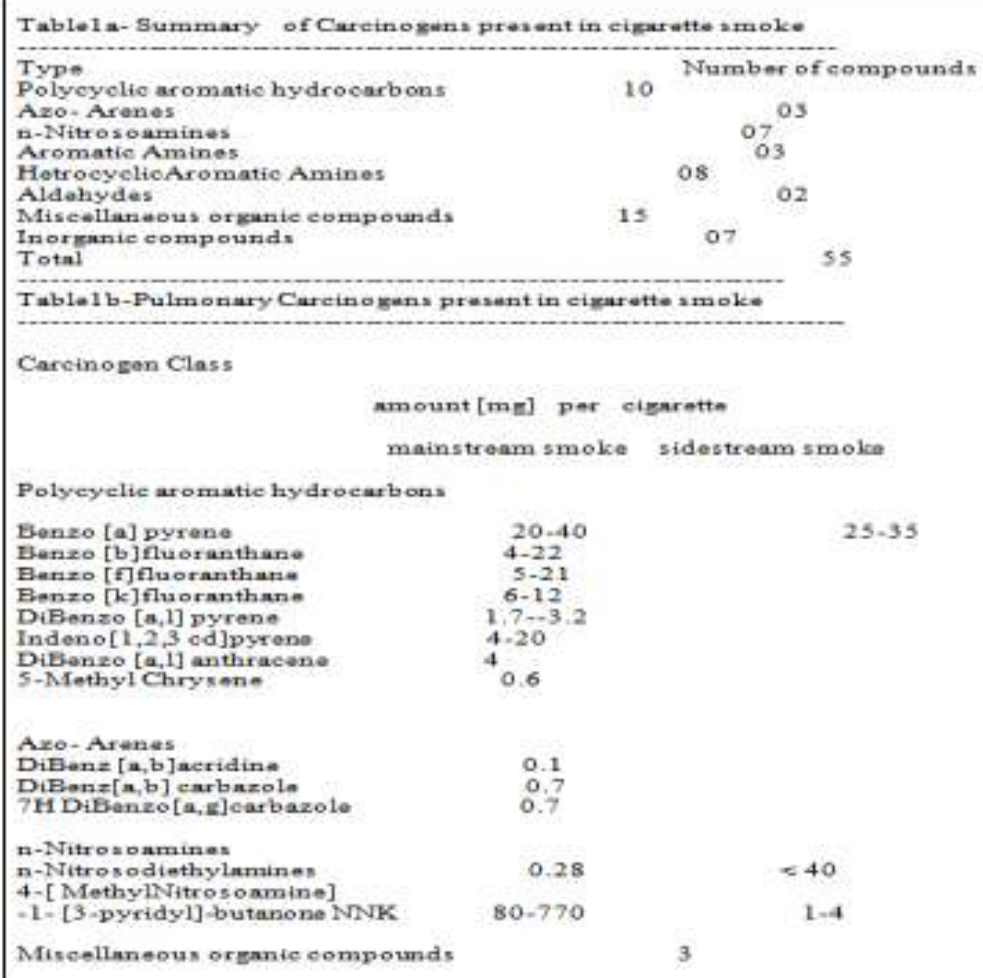




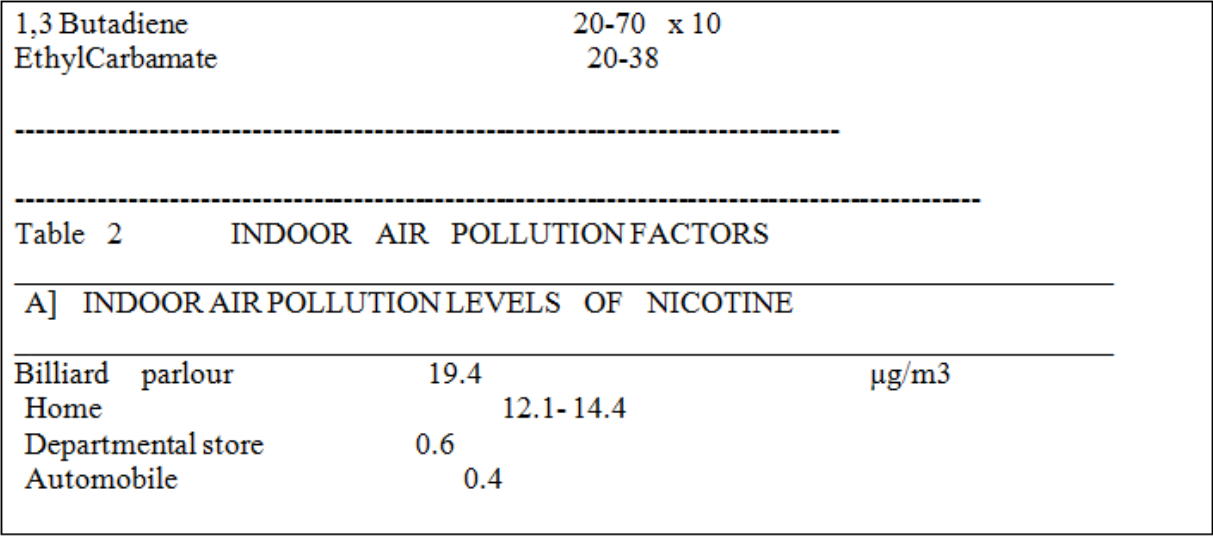

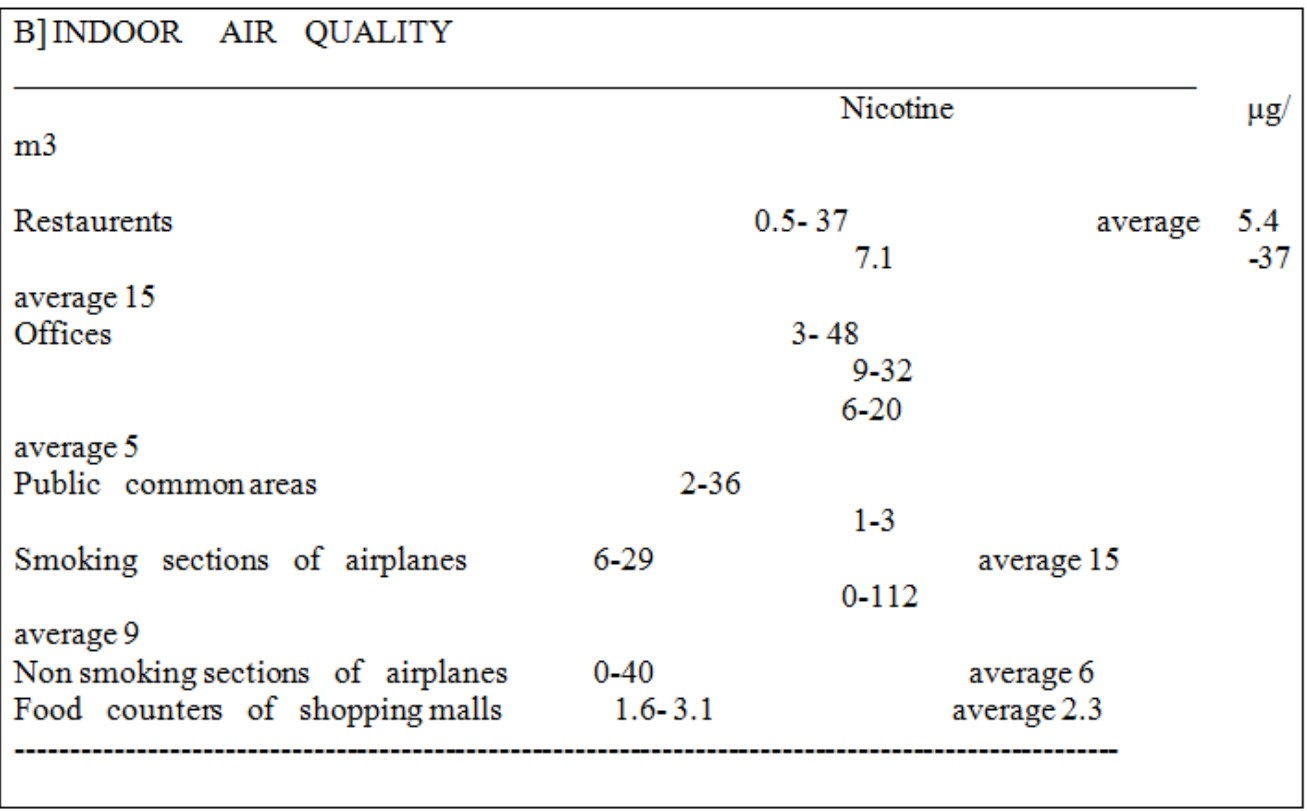

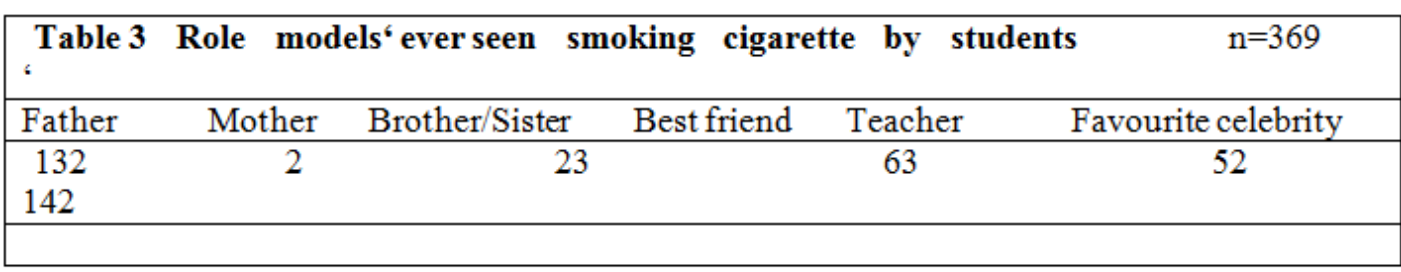

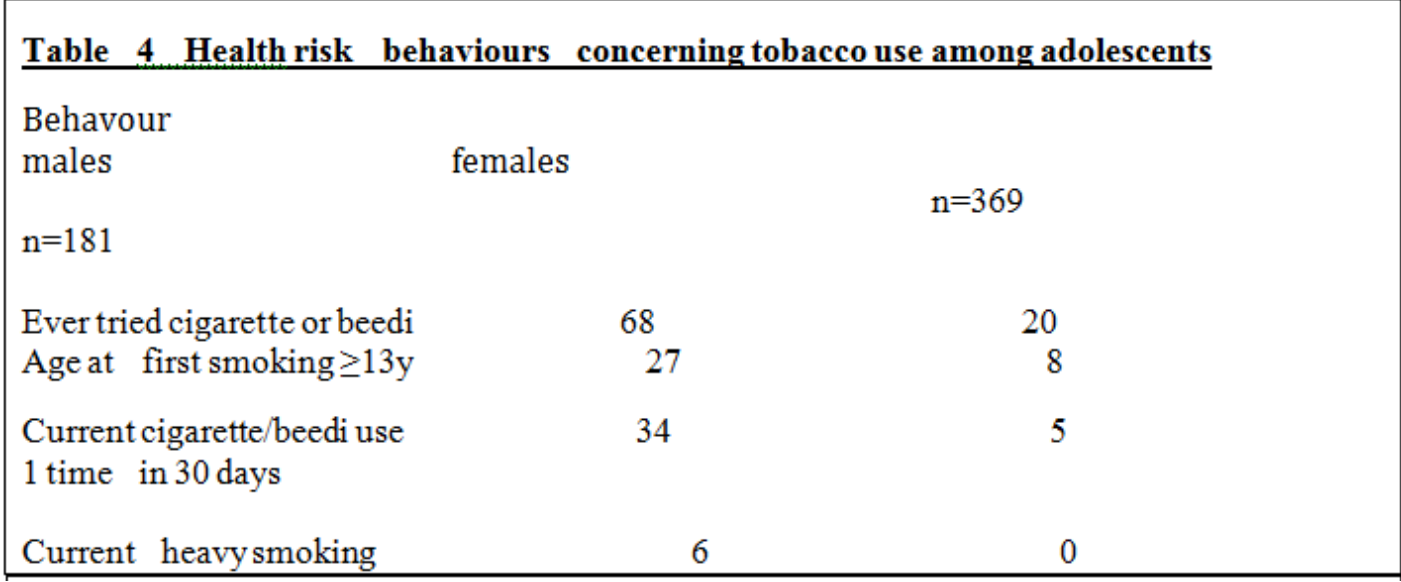

